\title{
O front como experiência da temporalidade: crise da civilização, falência representacional e alteridade
}

\author{
CARLOS HENRIQUE ARMANI*
}

\begin{abstract}
Resumo: Esse artigo é um estudo introdutório ao pensamento de alguns intelectuais sobretudo Eric Maria Remarque - que viveram durante a Primeira Guerra Mundial e testemunharam um período histórico profundamente conturbado pela violência e morte - a experiência da temporalidade. Para tal estudo, eu investigarei três tópicos no pensamento desses autores: a crise da idéia de civilização; os limites da representação como categoria cognitiva e a questão da alteridade.
\end{abstract}

Abstract: This article is an introductory study about the thought of some intellectuals above all Erich Maria Remarque - who lived the First World War and witnessed an historical period deeply disturbed by violence and death - the experience of temporality. For this study, I will investigate three topics in the thought of those intellectuals: the crisis of civilization idea; the limits of representation as cognitive category and the question of alterity.

Palavras-chave: Primeira Guerra Mundial. História. Temporalidade.

Key words: First World War. History. Temporality.

O historiador das idéias Franklin Baumer afirma que ainda está por ser feito um estudo acerca da experiência e do impacto da Primeira Guerra Mundial no pensamento dos intelectuais que, de um modo ou de outro, a viveram. ${ }^{1}$ Tomando tal desafio como ponto de partida, a minha proposta, nesse artigo, é fazer uma investigação introdutória sobre o pensamento da primeira metade do século XX na condição de testemunho histórico de um século profundamente conturbado pela guerra enquanto experiência por

* Doutorando em História - PUCRS; bolsista do CNPq.

E-mail: carlos.armani@gmail.com.

1 BAUMER, Franklin. O pensamento europeu moderno. Lisboa: Ed. 70, 1990, v. 2, p. 170.

Estudos Ibero-Americanos. PUCRS, Edição Especial, n. 2, p. 87-101, 2006 
excelência que demarca o mundo da finitude, ${ }^{2}$ ou da passagem do tempo para a (re)descoberta radical da temporalidade. ${ }^{3}$ Para tal proposta, tomarei como base de investigação o pensamento de alguns intelectuais que viveram a Primeira Guerra Mundial evento-limite traumático no século em que a catástrofe se tornou o seu principal documento -, especialmente o pensamento de Erich Maria Remarque.

Do ponto de vista da história intelectual, o século XX, de uma maneira geral, sobretudo nos seus primeiros anos, foi rico na produção de uma literatura da angústia, da alienação, do absurdo e da nadificação, o século que inaugura, nas palavras do filósofo Paul Tillich, "a era da ansiedade". ${ }^{4}$ Baumer afirma que a Primeira Guerra Mundial fez tremer os alicerces da vida e do pensamento europeu. Para o autor, "é inconcebível que um tal holocausto, que apanhou a maioria dos europeus de surpresa, não o tivesse feito". ${ }^{5}$ Muitos foram os autores que se depararam com a ansiedade existencial de um mundo cada vez mais destituído de fundamento e de ontologia. Sigmund Freud, Franz Kafka, Paul Tillich, Ernst Jünger, Karl Kraus, Franz Rosenzweig, Martin Heidegger, Franz Alexander, Henri Bergson, entre outros, direcionaram grande parte de suas energias intelectuais para colocar um dos problemas precípuos do homem: a finitude. Finitude que afastou definitivamente o ser, "deixando os homens sem pontos de referência e colocando-os à deriva num mar infinito de devir". ${ }^{6}$ Heidegger foi um dos filósofos que soube compreender de modo profundo essa dimensão ao colocar o tempo como horizonte de toda a compreensão e interpretação do ser7, compreensão que não era mais aquela, denunciada pelo próprio Heidegger, que acompanhava o pensamento desde Aristóteles e que tomava o tempo como medida do movimento - a "compreensão vulgar de tempo". 8

2 A finitude, aqui, está profundamente relacionada com a crítica heideggeriana da metafísica da subjetividade, que questiona a dupla capacidade do homem de estar consciente de si mesmo (auto-reflexão) e de fundar o seu próprio destino (a liberdade como autofundação). Como sabemos, o anti-humanismo, entre outros, de Heidegger, sustenta a finitude radical inultrapassável de nosso saber e do nosso poder em relação ao real. Ver: RENAUT, Alain. A era do indivíduo: contributo para uma história da subjectividade. Lisboa: Inst. Piaget, 1989, p. 17-18.

3 SOUZA, Ricardo Timm de. O tempo e a máquina do tempo: estudos de filosofia e pósmodernidade. Porto Alegre: EDIPUCRS, 1998, p. 140.

4 TILLICH, Paul. A coragem de ser. Rio de Janeiro: Paz \& Terra, 1976, p. 27.

5 BAUMER, op. cit., p. 170.

6 Ibid., 167.

7 HEIDEGGER, Martin. El ser y el tempo. México: FCE, 1974, p. 27.

8 HEIDEGGER, op. cit., p. 28. 
Mas esse sentimento de nadificação, de angústia, de medo, também foi constante em muitos homens que viveram, literalmente, no front da guerra. Nesse sentido, um dos maiores testemunhos sobre o horror da guerra é o pensamento de Erich Maria Remarque (1898-1970).

É importante enfatizar que, ao falar de testemunho, não estou preconizando qualquer tipo de lealdade teórico-metodológica à tradição cartesiana de clareza e distinção - a evidência - do pensamento que supostamente subsume o real a uma totalidade fornecida pela razão, como se o testemunho fosse a marca indelével da existência individual e sua peculiar relação "individualíssima" através da consciência - com a verdade. ${ }^{9}$ Pelo contrário, o testemunho, aqui, somente tem sentido se pensado em um contexto epistemológico em que o primado da substância - e da substância indivisível - é profundamente problematizado, ${ }^{10}$ o que implica, evidentemente, o questionamento, entre outros, da metafísica da subjetividade através da ontologia hermenêutica heideggeriana.

Remarque foi um jovem soldado alemão que serviu na Frente Ocidental durante a Primeira Guerra, da qual saiu profundamente traumatizado. Depois da guerra, grande parte de seus esforços intelectuais foram canalizados para a literatura, a qual se transformou em um dos principais marcos do pensamento antibelicista do século XX. Sua literatura pode ser concebida como um testemunho, uma espécie de fuga para frente em direção à palavra e um mergulhar na linguagem, como uma tentativa de libertação da cena traumática do front, ${ }^{11}$ trauma que não é mais do que essa experiência radical da temporalidade, a explosão e a pulverização da totalidade que nos leva a mergulhar em uma profunda crise de sentido da cultura cidental. ${ }^{12}$

Para efeitos didáticos, vou direcionar o texto para três temas que podem ser encontrados no pensamento de Remarque. ${ }^{13}$ São eles: a crise da idéia de civilização, a falência da representação

9 VATTIMO, Gianni. As aventuras da diferença. Lisboa: Ed. 70, 1988, p. 49.

10 Ver, a esse respeito, o capítulo $O$ ocaso do sujeito e o problema do testemunho, em: VATTIMO, op. cit., p. 49-67.

11 SELIGMANN-SILVA, Márcio. A história como trauma. In: NESTROWSKY, Arthur, SELIGMANN-SILVA, Márcio (orgs.). Catástrofe e representação. São Paulo: Escuta, 2000, p. 90.

12 SOUZA, Ricardo Timm de. Totalidade $\mathcal{E}$ desagregação: sobre as fronteiras do pensamento e suas alternativas. Porto Alegre: EDIPUCRS, 1996, p. 27.

13 O livro de Remarque foi consagrado não somente no mundo da literatura pacifista pós-Primeira Guerra Mundial, mas também nos cinemas, através de sua realização fílmica com Sem novidade no front, de Lewis Milestone (1895-1980), levado às telas em 1930, quando ganhou Oscar de melhor filme e de melhor diretor. 
enquanto categoria central do pensamento racionalista e a questão da alteridade enquanto encontro traumático com o outro. Essa divisão é apenas uma racionalização instrumental do texto, uma tradução que trai a inter-relação de cada um desses temas entre si. Ademais, tais temas não são uma propriedade do pensamento de Remarque, como já procurei salientar acima. Há, indubitavelmente, uma atmosfera de angústia e ansiedade partilhada por muitos intelectuais nesse período, alguns dos quais serão apresentados ao longo do texto.

\subsection{A crise da idéia de civilização}

Falar sobre os primeiros trinta anos do século XX é falar sobre um período balizado por uma profunda crise do projeto civilizacional ocidental, quando grande parte dos valores da sociedade racionalista do século XIX, consubstanciados na idéia de civilização na sua totalidade, encontrou seus limites em termos de realização. A Primeira Guerra assinalou o colapso da civilização ocidental, que até então exultava e cantava pelo mundo afora suas realizações em nome do progresso.

Muitos "fatos brutos" contribuíram para a crise, os quais proporcionaram aos homens do novo século um campo fértil de reflexão sobre aquilo que era o principal problema dos (novos) tempos: o próprio homem. Certamente, a Primeira Guerra Mundial foi um dos eventos-limite que mais contribuiu para esse mergulho na reflexão da condição existencial humana, afinal, nunca uma guerra havia matado, até então, tanta gente. Como sugere Hobsbawm, 1914 inaugurou uma guerra que foi travada pelas principais potências como um tudo ou nada, como uma guerra que só podia ser vencida por inteiro ou perdida por inteiro, simplesmente porque se tratava de uma guerra com metas ilimitadas. ${ }^{14}$

A Grande Guerra, como ficou conhecida entre seus contemporâneos, surgiu em um contexto romântico de entendimento da guerra, bem como num mundo que acreditava, em termos geopolíticos e darwinistas, de que ela era inevitável como forma de luta pela vida das nações. Nesse sentido, aquilo que parecia ser mais uma guerra entre outras - em uma Europa profundamente marcada pela realidade heraclitiana que afirma a guerra como o pai de todas as coisas ${ }^{15}$-, se transformou na Grande Guerra, a qual alcan-

14 HOBSBAWM, Eric. A era dos extremos. São Paulo: Cia das Letras, 1995, p. 37.

15 Não vou entrar na discussão sobre a guerra/conflito - pólemos - tal como Heráclito a pensava. A referência que faço a Heráclito é apenas ilustrativa e ressignificada para 
çou contornos mundiais e se transformou num confronto bélico de trincheiras onde o sentimento de nadificação e de finitude, enquanto enfrentamento com a alteridade da morte, andava lado a lado com os homens cujos rostos enlameados desapareciam na tenebrosa impessoalidade do front.

Tal crise não poderia deixar de ser salientada por um intelectual-soldado do front, como Remarque. Entendo que o front, nesse sentido, era uma espécie de metonímia do mundo ocidental, e não somente o front enquanto um espaço físico de combates rigidamente demarcado em uma dada região da Europa. ${ }^{16}$ Portanto, o front, a Frente Ocidental e o Ocidente eram partes de uma mesma idéia que poderia ser traduzida como civilização. Essa passagem, de Remarque, nos indica a crise pela qual a idéia de civilização, de cultura e de progresso foi posta em xeque:

Como é inútil tudo quanto já foi escrito, feito e pensado, quando não se conseguem evitar essas coisas! [Remarque referia-se à quantidade de hospitais espalhados pela Alemanha, pela França e pela Rússia para tratar de todos os feridos da guerra]. Devem ser mentiras e insignificâncias, quando a cultura de milhares de anos não conseguiu impedir que se derramassem esses rios de sangue e que existam aos milhares estas prisões, onde se sofrem tantas dores. Só o hospital mostra realmente o que é a guerra. ${ }^{17}$

Parte dessa citação poderia ser atribuída a Freud, para quem a civilização somente existia às expensas da felicidade. É possível perceber no pensamento de Remarque uma profunda dissociação da idéia de felicidade em relação à civilização. A inutilidade do que foi pensado, escrito e construído não serviu para evitar a catástrofe da guerra. O homem do tempo de Remarque, sobretudo

o caso que estou investigando. Seguramente, o pólemos de Heráclito é muito mais rico em termos de significação do que a adjetivação que faço nesse artigo.

16 Seria possível pensar metonimicamente o front de Remarque - ou seja, as principais trincheiras ocupadas por ele e suas tropas - como a Frente Ocidental em sua totalidade, haja vista que esta ficou conhecida justamente em razão dessas trincheiras construídas paralelamente em uma larga extensão territorial. Nesse sentido, o front de Remarque não seria parte da Frente Ocidental, mas a Frente Ocidental em sua totalidade. Tal relação entre parte e todo aparece em uma tradução do livro de Remarque feita para o português em 1930, em que o título é Nada de novo na Frente Ocidental. O mesmo se pode dizer do filme de Milestone, que no original se chama All quiet on the western front, novamente uma referência à Frente Ocidental. Em relação ao livro de Remarque, no original, parece ser possível fazer a mesma leitura, posto que o título é Im Westen nichts neues. Ou seja, "Nada de novo no Ocidente".

17 REMARQUE, Erich Maria. Nada de novo no front. Porto Alegre: L\&PM, 2004, p. 201. Edição alemã: REMARQUE, Erich Maria. Im Westen nichts neues. Frankfurt: Ullstein Buch, 1960. Para as citações posteriores, vou usar sempre a edição em língua portuguesa. Em algumas passagens, vou fazer referência ao texto original. 
aqueles que partilharam com ele a realidade da guerra, não eram felizes: "Sou jovem, tenho vinte anos, mas da vida conheço apenas o desespero, o medo, a morte e a mais insana superficialidade que se estende sobre um abismo de sofrimento". ${ }^{18}$ Essa passagem, uma referência que Remarque fez a si próprio através do personagem Paul Bäumer, poderia ser extensiva à grande parte de sua geração. ${ }^{19}$ Ainda de acordo com ele:

Os professores deveriam ter sido para nós os intermediários, os guias para o mundo da maturidade, para o mundo do trabalho, do dever, da cultura e do progresso e para o futuro [...] À idéia de autoridade da qual eram os portadores, juntou-se em nossos pensamentos uma melhor compreensão e uma sabedoria mais humana. Mas o primeiro morto que vimos destruiu essa convicção [...] O primeiro bombardeio nos mostrou nosso erro, e debaixo dele ruiu toda a concepção de mundo que nos tinham ensinado. 20

Há uma profunda disjunção entre o que Remarque aprendeu na escola, e o que viveu na guerra. Se a concepção de mundo otimista - que havia aprendido ruiu frente ao primeiro morto que tombou em sua frente, o aprofundamento da guerra e a multiplicação aos milhares desses mortos, fez de Remarque um homem que não via mais razão para lutar em nome de uma civilização. Era ela própria a responsável por esses males. Toda a cumulatividade da experiência civilizacional não serviu para nada, ou pelo menos não foi canalizada para os esforços de paz. Para quem poderia servir o progresso se ele não impediu o massacre de milhares de pessoas?

Talvez tal visão possa parecer um pouco trivial atualmente, haja vista a quantidade e a densidade das críticas ao progresso realizadas ao longo dos últimos 50 anos. Certamente, não o era num período que ainda exultava com todos os avanços da ciência e do mundo da cultura.

18 REMARQUE, op. cit., p. 201.

19 Essa experiência da guerra não pode ser generalizada, mesmo entre aqueles que engrossaram as fileiras dos combatentes. Para um autor como Ernst Jünger, por exemplo, a guerra havia tornado os homens brutos, os quais formariam uma nova ideologia que tinha impressa as características do materialismo e da brutalidade. Ver: BAUMER , op. cit., p. 174. De acordo com Hobsbawm, quase todos os que serviram na Primeira Guerra Mundial saíram dela como seus inimigos convictos. Por outro lado, vários ex-soldados que haviam passado por aquele tipo de guerra sem se voltarem contra ela às vezes extraíam da experiência partilhada de viver com a morte e a coragem um sentimento de incomunicável e bárbara superioridade, o que viria a formar as primeiras fileiras da ultradireita do pós-guerra, entre eles, Hitler e a sua crença de que o fato de ter sido soldado do front era a experiência formativa da vida. Ver: HOBSBAWM, op. cit., p. 34 .

20 REMARQUE, op. cit., p. 18. Concepção de mundo: "Weltanschauung", no original. 
Os homens, disse Freud em um escrito do mesmo período, "se orgulham de suas realizações e têm todo o direito de se orgulharem. Contudo, parecem ter observado que o poder recentemente adquirido sobre o espaço e o tempo", assim como "a subjugação das forças da natureza [...] não aumentou a quantidade de satisfação prazerosa que poderiam esperar da vida e não os tornou mais felizes". ${ }^{21}$ Freud parecia assistir à desagregação de uma sociedade cuja estrutura espaço-tempo havia sido, até então, rígida, sólida e durável.22

O psicanalista austríaco fazia vistas grossas, assim como uma quantidade crescente dos seus contemporâneos, ao progresso da ciência e da técnica. Ademais, o homem, criador de ciência, de filosofia, de cultura, não era uma "criatura gentil" que desejava ser amada, mas pelo contrário, afirmou Freud, "são criaturas entre cujos dotes instintivos deve-se levar em conta uma poderosa quota de agressividade". ${ }^{23}$ Para fundamentar essa asserção, demasiadamente negativa em relação ao homem, Freud mencionou "várias atrocidades cometidas pela humanidade", entre elas, "os horrores da recente guerra mundial". ${ }^{24}$

De acordo com Freud, a inclinação para a agressão poderia ser encontrada em toda a humanidade, e se constituía no principal fator que perturbava o relacionamento com o próximo, forçando a civilização a um elevado dispêndio de energia para reprimir os instintos agressivos do homem. Por mais que Freud tentasse estabelecer uma certa disjunção entre a natureza agressiva do homem e a civilização, tentando poupá-la do mal-estar na cultura, suas palavras não parecem ecoar qualquer tipo de otimismo em relação à própria civilização.

O psiquiatra Franz Alexander partilhava de algumas das idéias de Freud e de Remarque. Um de seus livros mais conhecidos, Our age of unreason, foi escrito "sob a influência das profundas mudanças culturais nos anos que se seguiram à Guerra Mundial". 25 Alexander acreditava estar testemunhando o processo de dissolução de uma época cultural, a desintegração e o desaparecimento de padrões e ideais que até então haviam sido para ele como uma

21 FREUD, Sigmund. O mal-estar na civilização. Rio de Janeiro: Imago, 1997, p. 39.

22 BAUMAN, Zygmunt. O mal-estar da pós-modernidade. Rio de Janeiro: Zahar, 1998, p. 110.

23 FREUD, op. cit., p. 67.

24 Ibid., p. 68.

25 ALEXANDER, Franz. Our age of unreason. In: BAUMER, Franklin. Main currents of western thought: readings in western European intellectual history from the Middle Ages to the present. Yale: Yale University Press, 1978, p. 657. 
espécie de segunda natureza.26 Apesar de sua tentativa de poupar a razão - como Freud fizera em relação à civilização - do mal-estar vivido pelos homens, Alexander entendia que as ciências haviam falhado em desenvolver a felicidade humana. ${ }^{27}$

Por fim, como deixar de mencionar, nesse sentido, Fernando Pessoa? Em uma passagem do poema Lisbon Revisited, eis o que diz o poeta na voz de um de seus heterônimos - Álvaro de Campos:

NÃO: NÃO quero nada.

Já disse que não quero nada.

Não me venham com conclusões!

A única conclusão é morrer.

Não me tragam estéticas!

Não me falem em moral!

Tirem-me daqui a metafísica!

Não me apregoem sistemas completos, não me enfileirem conquistas

Das ciências (das ciências, Deus meu, das ciências!) -

Das ciências, das artes, da civilização moderna!.28

Estavam rompidos, ou seriamente abalados, os laços de cumulatividade da experiência passada com o presente e com o futuro.

\subsection{Os limites da representação}

A representação - o triunfo do objeto ausente feito simplespresença enquanto re-apresentar-se para o intelecto, uma tradução do mundo dos fatos para o lingüístico 29 - se choca de modo mais contundente com a realidade do front. Como representar, via imagens discursivas, a realidade de uma guerra mundial? Essa parece ser uma das questões cruciais com a qual vários intelectuais se depararam e que nos encaminha para o segundo tema proposto nesse artigo.

Como descreve Remarque, "os dias na frente [...] caem dentro de nós como pedras; são pesados demais para podermos refletir tão depressa sobre eles". ${ }^{30}$ Ou ainda, no diálogo de Paul Bäumer - protagonista do romance de Remarque e seu alter ego - com sua mãe

26 ALEXANDER, op. cit., p. 657.

27 Uma leitura assaz interessante dessa relação conflituosa do homem consigo mesmo é apresentada de modo impressionante no aforismo 16 de Genealogia da moral, quando Nietzsche disserta acerca da origem da má consciência. Ver: NIETZSCHE, Friedrich. Genealogia da moral. São Paulo: Cia. das Letras, 1998, p. 72-73.

28 PESSOA, Fernando. Poesia/Álvaro de Campos. São Paulo: Cia. das Letras, 2002, p. 245.

29 SELIGMANN-SILVA, op. cit., p. 76.

30 REMARQUE, op. cit., p. 113. 
que, ao lhe perguntar sobre a vida nas trincheiras, ouve a seguinte resposta: "mãe, que devo responder a isso? Você não entenderia e nunca poderia imaginá-lo. E não deveria imaginá-lo". ${ }^{31}$ Clareza, certeza e distinção não pareciam ser qualidades apreciáveis para o homem do front, que temia transformar os acontecimentos em palavras. "É muito perigoso para mim", é Bäumer (Remarque) quem fala novamente, "transformar os acontecimentos em palavras: tenho medo de que eles então se agigantem de tal modo que eu não consiga mais dominá-los". "Onde estaríamos", conclui o jovem soldadoescritor, "se tudo que nos acontece no campo de batalha fosse muito claro para nós?". 32

A dificuldade em construir uma representação ainda era mais difícil nos momentos em que estava em jogo, de modo mais explícito, a relação do presente com o passado, tal como aparece nessa passagem:

Para mim, é estranho pensar que, em casa, numa gaveta de escrivaninha, há um começo de drama - Saul - e um monte de poemas. Quantas noites passei trabalhando neles; quase todos nós fazíamos algo semelhante; mas tudo ficou tão irreal para mim, que não consigo representar nitidamente os fatos na memória. ${ }^{33}$

O rompimento desse elo temporal foi uma questão com a qual Remarque se debateu em muitos momentos de sua obra: "Muitas vezes, vejo-me diante de mim mesmo como diante de um estranho, quando encontro o reflexo enigmático do passado [...] como um espelho embaçado, que revela o perfil de minha vida atual". ${ }^{34}$

O espelho é a imagem clara da identidade, da representação. Mas, um espelho embaçado cujo reflexo enigmático revelaria um perfil, o perfil de uma vida dilacerada pelo rompimento com o passado, pela violência e pela dor de uma guerra mundial, é o testemunho de que a representação tornou-se, tal como o homem, problemática. Problemática também porque ela não conseguia mais apreender o empírico, cujo tempo não era mais aquele medido pelo relógio ou que pudesse ser subsumido dialeticamente por

31 Ibid., p. 129. Mãe, que devo responder...: "Mutter, was soll ich darauf antworten? Du wirst es nicht verstehen und nie begreifen. Du sollst es auch nie begreifen". Para os propósitos desse estudo, talvez fosse melhor traduzir o verbo "begreifen" por compreender, entender, no sentido de uma idéia, um conceito. O substantivo correspondente é "Begriff", que pode ser traduzido como conceito, noção, idéia, representação.

32 Ibid., p. 132.

33 Ibid., p. 23. Mas tudo ficou... "Aber es ist mir so unwirklich geworden, dass ich es mir nicht mehr richtig vorstellen kann”.

34 REMARQUE, op. cit., p. 207. 
um espírito absoluto. Podemos perceber, em Remarque, a falência conceitual, a compreensão dos limites da própria compreensão, a realidade na sua irredutibilidade que desafia o pensamento racional, agora não mais a única - e talvez a menos relevante - qualidade do homem. Ortega y Gasset chama a atenção para esse limite da representação/conceito. Para o filósofo, os fenômenos humanos mostram a "mesma resistência, a mesma indocilidade em deixar-se apresar por conceitos". 35

A afirmação de um mundo de circunstâncias que se tornavam cada vez mais desconhecidas e estranhas para o ser humano, metaforizadas no espelho como imagem disforme, é uma qualidade precípua do desespero epistemológico, desespero que significa a aflição em conhecer, alguma vez, o que é o homem, ${ }^{36}$ um ver a si mesmo como estranho. O mundo havia se tornado desconhecido, sem precedentes no passado, e habitá-lo nesse oceano de incerteza era viver quase que sem fundamentos.

Como não pensar, aqui, em outros autores contemporâneos de Remarque, como Kafka, por exemplo? Odradek (a criatura improvável), Gregor Samsa, o médico da aldeia e o "seu" "tempo da angústia", ou ainda o agrimensor K., que percorre os "caminhos eternamente vazios" 37 que rodeiam o Castelo ao qual ele pretende chegar, são personagens e enredos que evocam não somente $o$ desespero epistemológico, mas o profundo mergulho do homem contemporâneo na temporalidade. 38

Seligmann-Silva, ao falar sobre a representação no eventolimite traumático, pergunta: "Seria possível dar forma ao irrepresentável? Como dar forma ao que transborda a nossa capacidade de pensar?". ${ }^{39} \mathrm{O}$ excesso, o transbordamento dos conceitos, o "algo" que vai "além de nossa capacidade de imaginar e representar", estão profundamente relacionados à cena traumática do front. SeligmannSilva, na esteira de Freud, afirma que o trauma é uma ferida na memória, a incapacidade de recepção de um evento transbordante, "de um evento que vai além dos 'limites' da nossa percepção e torna-se para nós, algo sem-forma (grifos do autor)". ${ }^{40}$ É novamente Remarque quem fala: "Hoje, passaríamos pela paisagem de nossa juventude

35 ORTEGA Y GASSET, José. Historia como sistema y otros ensayos filosóficos. Madrid: Alianza Editorial, 1981, p. 29.

36 BAUMER, O pensamento..., op. cit., p. 185.

37 KAFKA, Franz. O castelo. São Paulo: Cia. das Letras, 1995, p. 186.

38 Ver, a propósito dessa questão relativa à temporalidade em Kafka: SOUZA, Ricardo Timm. Metamorfose e extinção: sobre Kafka e a patologia do tempo. Caxias do Sul: EDUCS, 2000.

39 SELIGMANN-SILVA, op. cit., p. 83.

40 Ibid., p. 84. 
apenas como viajantes. Os fatos nos consumiram [...] Vivemos numa terrível indiferença". "Se estivéssemos lá", Remarque se referia à vida anterior à guerra, "será que viveríamos? Desamparados como crianças e experientes como velhos, somos primitivos, tristes e superficiais... Acho que estamos perdidos". ${ }^{41}$

Como construir uma representação da guerra, se os fatos esgotaram o homem? Que sentido de realidade poderia ser construído a partir dessa experiência traumática, se a própria abstração não parecia mais fazer muito sentido? Remarque parecia testemunhar não somente tal falência representacional, mas, ainda mais, a morte do ser ou a sua relação radical com o tempo, o seu ser-aí, as suas circunstâncias, o seu ser-para-a-morte. Como encontrar novamente o fundamento, num mundo de indiferença e superficialidade, num mundo em que se rompeu definitivamente o cordão com o passado, onde a paisagem da juventude era apenas uma passagem, a passagem de viajantes que não tinham mais qualquer morada no espaço e no tempo, uma passagem para o nada?

O nada, cada vez mais presente na literatura, era a ameaça do não-ser, um estado no qual um ser teria ciência de seu possível nãoser e a ansiedade, uma consciência existencial do não-ser. ${ }^{42}$ Paul Tillich, já mencionado no início do texto, entendia que havia três tipos de ansiedade de acordo com três direções em que o não-ser ameaçava o ser: "na auto-afirmação ôntica do homem, de modo relativo, em termos de destino, de modo absoluto, em termos de morte"; na auto-afirmação moral do homem, "de modo relativo em termos de culpa, de modo absoluto em termos de condenação" e, por fim, o não-ser ameaçava o ser do homem na sua "auto-afirmação espiritual, de modo relativo em termos de vacuidade, de modo absoluto, em termos de insignificação". ${ }^{43} \mathrm{O}$ momento presente, vivido por Remarque, Freud, Alexander, Tillich e milhares de outros homens era, nas palavras daquele último, um período de predomínio da ansiedade do vazio e de ausência de significado, do duvidar não mais como princípio metodológico, mas como desespero existencial. ${ }^{44}$ Como dissociar, aqui, a crise da civilização de todo aquele processo de nadificação como experiência radical da temporalidade que atestava o ocaso da representação e a emergência/redescoberta da alteridade?

41 REMARQUE, op. cit., p. 101.

42 TILLICH, op. cit., p. 28.

43 TILLICH, op. cit., p. 32.

44 Ibid., p. 37. 


\subsection{A questão da alteridade}

Encontrar um rosto, expressar o encontro que seria a alteridade não poderia se realizar, nesse contexto, se não fosse traumático. Remarque viveu a alteridade da guerra, uma alteridade tênue, que constantemente demarcava sua fronteira com a indiferença e a impessoalidade.

Nesse momento, a atividade do pensamento passa a ser não mais um contemplar, mas um "engajar-se", um acontecimento dramático do ser-no-mundo". ${ }^{45}$ Acontecimento dramático que hipertrofia o processo de desidentificação entre pensamento e ser.

Poderíamos falar do absolutamente outro em relação ao si mesmo de Remarque, seu estranhamento, sua dor, e todo aquele presente absoluto que permanece irredutível às suas reflexões. Penso, contudo, que há uma passagem, em particular, bastante relevante do pensamento de Remarque a respeito da alteridade. Trata-se do momento em que o personagem Bäumer, escondido em uma vala, é encontrado por um soldado inimigo. Os dois iniciam uma luta corpo a corpo e Bäumer fere o soldado mortalmente. Mas a sua morte não é instantânea. Bäumer - diante do fogo cerrado e do bombardeio intenso - é impedido de sair da vala onde ele havia se escondido, o que lhe obriga a dividir aquele espaço com o soldado moribundo que agoniza, um espaço que se torna, por sua vez, moribundo e agonístico também. Essa passagem, relativamente extensa, merece ser apresentada aqui. Depois de passar a noite na vala junto com o soldado, eis o que diz Bäumer:

$\mathrm{O}$ vulto se mexe. Estremeço e, sem querer, olho na sua direção. Meus olhos então ficam como que colados a ele. É um homem com pequeno bigode, estendido ali, com a cabeça caída para o lado [...]. Está morto, digo a mim mesmo, deve estar morto, já não sente mais nada; é apenas o corpo que está ali, agonizando. Mas a cabeça tenta erguer-se: por um instante, os gemidos tornam-se mais fortes [...]. O homem não está morto: está morrendo, mas ainda vive. Rastejando, aproximo-me dele; paro; apóio-me nas mãos e torno a rastejar mais um pouco; espero, torno a avançar; é uma dolorosa jornada de três metros, uma longa e terrível jornada. Finalmente, estou a seu lado. Agora, abre os olhos. Deve ter me ouvido, e me olha com uma expressão de absoluto pavor [...]. O corpo está imóvel, sua imobilidade é total: não se ouve um só ruído, cessou o estertor, mas os

45 LÉVINAS, Emmanuel. Entre nós: ensaios sobre a alteridade. Petrópolis: Vozes, 2005, p. 23. 
olhos gritam, urram: neles, juntou-se toda a vida que ainda resta, num esforço sobre-humano para escapar, um pavor atroz diante da morte, diante de mim [...]. Os olhos seguem-me. Sinto-me incapaz de fazer um movimento sequer, enquanto estiverem cravados em mim [...]. Preciso mostrar que quero ajudá-lo; passo a mão em sua testa [...]. Quero ajudar você, companheiro, camarade, camarade, camarade - repito insistentemente a palavra, para que ele compreenda [...]. Este é o primeiro homem que matei com minhas próprias mãos e cuja morte, posso constatá-lo sem sombra de dúvida, foi obra minha [...]. Mas cada respiração arquejante corta meu coração. Este ser que agoniza tem o tempo do seu lado, possui um punhal invisível, com que me fere: o tempo e meus pensamentos [...]. - Companheiro, não queria matá-lo. Se voltasse novamente aqui para dentro, não o faria, se você também fosse razoável. Mas, antes, você era apenas um pensamento, uma dessas abstrações que povoam meu cérebro e que exigem uma decisão... Foi essa abstração que apunhalei. Mas agora, pela primeira vez, vejo que é um ser humano como eu. Pensei nas suas granadas, na sua baioneta e no seu fuzil. Agora, vejo sua mulher, seu rosto [...]. Seu nome é um prego que será cravado em mim e nunca mais poderá ser arrancado. Terá o poder de me fazer recordar tudo, para sempre... ${ }^{46}$

Aquilo que primeiramente é um vulto torna-se uma imagem assombrosa para Bäumer, cujo desejo é apenas manter-se distante daquela alteridade, alteridade que não se circunscreve somente à radicalidade da morte, vivida pelo outro. De repente, o vulto tem olhos, tem rosto. Há uma aproximação. Há um encontro, cujo tempo inicial de realização é a eternidade de alguns segundos de Bäumer rastejando ao encontro do soldado moribundo, um encontro em que o outro vive a radicalidade da experiência de sua finitude diante de seu horror à morte que se aproxima, não somente aproximação que se dá pelos ferimentos graves, mas pela aproximação daquilo que para o outro é a morte, a sua morte: o soldado Bäumer. E Bäumer percebe que todo o grito e estertor no olhar daquele homem era vida, uma vida desesperada que se esvai na sua irredutibilidade. No encontro, Bäumer entende que o que ele fez não foi matar uma representação, uma abstração, um ente que seria parte de uma totalidade, de um ser, mas um ente que se apresentava como tal. Como sugere Lévinas, ao referir-se à alteridade, "na nossa relação com outrem, este não nos afeta a partir de um conceito. Ele é ente e conta como tal". ${ }^{47}$ É esse contar como tal do ente que atormenta o jovem soldado

46 REMARQUE, op. cit., p. 169-173.

47 LÉVINAS, op. cit., p. 26. 
alemão. Não se trata mais de nenhuma representação, de um conceito, mas do outro que está no frente a frente. $\mathrm{O}$ desespero maior de Bäumer é que naquele momento, não há qualquer universalidade, não há qualquer ontologia que possa lhe salvar daquele traumatismo. As suas tentativas para fazê-lo, ao descobrir o nome do soldado - Gerard Duval - e sua profissão - tipógrafo - são estéreis. Nem seu desejo momentâneo de tornar-se também tipógrafo - assumir o "outro" ontologicamente - consegue se manter diante daquele encontro. É uma compreensão que somente ocorre no ser que aquele ente encarna. Tudo se esvai na radicalidade do encontro. Novamente seguindo o pensamento levinasiano, o encontro com outrem consiste no fato de que, "apesar da extensão da minha dominação sobre ele e de sua submissão, não o possuo". $48 \mathrm{O}$ fato de matar Duval aumenta em Bäumer a angústia de seu não-possuir-o-outro, afinal, outrem é "o único ser que posso querer matar", mas um querer cujo poder é a própria derrota do poder, pois no "preciso momento em que meu poder de matar se realiza, o outro se me escapou". ${ }^{49}$ Não se trata, portanto, de um encontro edificador. A alteridade desse encontro é traumática.

Aqui, podemos voltar para o tema anterior, posto que a alteridade se coloca como sintoma de uma falência representacional. A situação-limite daquela aproximação resulta no que Seligmann-Silva fala a respeito da representação: "o momento de universalização que está na base da representação é destruído devido à singularidade do evento-limite". 50

\section{Considerações finais}

Evidentemente, falar do século XX, especialmente em seus primeiros 30 anos, é mergulhar no mundo da temporalidade. O pensamento de Remarque e de muitos dos seus contemporâneos apresentam um rico testemunho - como ocaso do sujeito cartesiano - de um tempo profundamente sombrio que permeia a

48 REMARQUE, op. cit., p. 31. Essa passagem é bem reproduzida por Lewis Milestone em seu filme, não obstante a ausência de uma apresentação mais sistemática das reflexões do soldado Bäumer, que foram, de certo modo, transpostas para as expressões faciais de cada um dos soldados na cena da vala.

49 LÉVINAS, op. cit., p. 31.

50 SELIGMANN-SILVA, op. cit., p. 87. 
construção/desconstrução de nossa própria idéia de humano, ${ }^{51}$ a qual se mantém, para citar uma expressão de Bhabha usada em outro contexto, entre a sombra e a substância. ${ }^{52}$ Lévinas afirma que o humano é um escândalo no ser. ${ }^{53}$ Ao encontro do filósofo, penso que, se a questão da temporalidade e da alteridade foi um tema que esteve no pensamento desde os seus primórdios, ${ }^{54}$ foi o século XX, contudo - com suas duas grandes guerras mundiais que hipertrofiou as dimensões desse escândalo na ontologia. A Primeira Guerra Mundial foi talvez, no século passado, o primeiro grande passo para o abismo do ser. ${ }^{55}$

A experiência da finitude e da temporalidade nos convida para uma relação que não pode se fechar em uma totalidade nem se cristalizar em representações e conceitos.

51 Como sugere Souza, a questão do humano é uma questão de temporalidade, e a temporalidade, "em seu sentido vital, é uma questão de 'construção' e 'desconstrução' do humano". Ver: SOUZA, Ricardo Timm de. Metamorfose e extinção..., op. cit., p. 13.

52 BHABHA, Homi. O local da cultura. Belo Horizonte: Ed. da UFMG, 1998, p. 82.

53 LÉVINAS, op. cit., p. 157.

54 De acordo com Souza, "o pensamento ocidental se estrutura, desde os seus primórdios, em torno à questão da diferença. É em torno a este núcleo referencial que os grandes problemas clássicos da filosofia se articulam e amadurecem enquanto, exatamente, problemas fundamentais". Ver: SOUZA, Ricardo Timm de. Sentido e alteridade: dez ensaios sobre o pensamento de Emmanuel Lévinas. Porto Alegre: EDIPUCRS, 2000, p. 189-190.

55 Não falo da temporalidade em um sentido reativo e negativo; pelo contrário, penso que, mesmo em se tratando de um século permeado pela catástrofe, é não somente possível, mas também afirmativo pensar a experiência da finitude tal como sugere Fernando Pessoa nessa passagem de $O$ guardador de rebanhos, de Alberto Caeiro: "Sinto-me nascido a cada momento, para a eterna novidade do mundo...". Ver: PESSOA, Fernando. Poesia completa de Alberto Caeiro. São Paulo: Cia. das Letras, 2005, p. 19. É importante notar que, no poema, ao se referir ao adjetivo "eterna", cinco adjetivos variantes aparecem em seu lugar também, tais como "perpétua", "serena", "grande", "completa" e "súbita", sem nenhum ser escolhido ou sequer preferido, sendo que cada um deles vem alterar o sentido e encaminhá-lo em uma direção diferente. Ver, a esse respeito, a nota prévia da edição acima citada. 